\title{
The impact of perfectionism on anxiety and depression.
}

\author{
David S Lessin, Nadira T Pardo* \\ California Southern University, USA
}

\begin{abstract}
Although perfectionism does not have its own diagnostic criteria in the DSM, clinicians need to be aware of its relationship to and impact upon depression and anxiety. This article will provide a brief overview of the research in this area, defining and exploring its etiology and how the most effective therapeutic interventions can help clients who suffer from it and also have issues with anxiety or depression.
\end{abstract}

Keywords: Perfectionism, Depression, Anxiety, Therapeutic interventions.

Accepted on March 23, 2017

\section{Introduction}

The last half-century has witnessed an outpouring of literature aimed at understanding the personality trait of perfectionism. Explanations for the relentless pursuit of flawlessness have developed over the years as theorists have gradually arrived at deeper insights into this debilitating problem. Researchers have shown clear causal links between perfectionistic tendencies, such as fear of making mistakes, exceedingly high personal expectations and harsh inner self talk and the prevalence of psychological disorders such as anxiety, eating disorders, depression and suicide $[1,2]$. Clinicians continue to investigate the etiology of perfectionism while seeking to develop effective treatment strategies to help those suffering in ways that inhibit work and life satisfaction, wreak havoc on interpersonal relationships, and erode feelings of self-worth.

\section{What is Perfectionism?}

Two independent teams of researchers have developed multidimensional perfectionism scales (MPS) to pinpoint underlying mechanisms that contribute to the active pursuit of perfection [2]. The Frost MPS scale is composed of six factors that are commonly displayed by perfectionists [3]. They are excessive concern over making mistakes, high personal standards, doubts about the quality of their actions, perception of high parental expectations, perception of parental criticism, and a preference for organization and orderliness. Around the same time, Hewitt and Flett were devising a separate MPS that consists of three types of perfectionism: OtherOriented, Self-Oriented and Socially Prescribed [1]. OtherOriented Perfectionism refers to the perfectionist's demand that others meet exaggerated and unrealistic standards. SelfOriented Perfectionism relates to the exceedingly high, selfimposed, unrealistic standards that perfectionists feel they must meet. They are unable to accept flaws or shortcomings in themselves, and engage in intense self-scrutiny when they encounter any sign of personal failure. The third form, Socially Prescribed Perfectionism, is maintained by a belief that others hold exaggerated expectations that are nearly impossible to meet, but that must be reached in order to gain approval and acceptance. This type of perfectionism combines intrapersonal achievement stressors with perceived interpersonal pressure [4]. Blatt points out that the combination of Self-Oriented and Socially Prescribed Perfectionism, which exist together in many perfectionists, produce a debilitating sense of constant personal failure accompanied with the belief that one has fallen short of earning the approval of the people who matter most [2]. These perceived external evaluations might come from contemporary figures or people from the individual's past whose judgment holds a central place in the person's mind. The resulting sense of isolation and having nowhere to turn can produce feelings of helplessness and utter despair [5].

Dunkley and Blankstein add an important point of analysis to the discussion of perfectionism [6]. They noticed that although the literature had pointed to the conceptual overlap between self-criticism and perfectionism [2] in that both involve a "chronic fear of disapproval, criticism, and rejection", no theorist had explicitly included self-criticism as a component of perfectionism. Dunkley and Blankstein's construct of selfcritical perfectionism formally combines these constructs [6]. Sherry posits that self-critical perfectionism involves four constructs described earlier in the literature [7]: self-criticism [2], socially prescribed perfectionism [1], concern over mistakes, and doubts about actions [3].

\section{Adaptive and Maladaptive Perfectionism}

Not all perfectionism is bad, and in fact certain components of perfectionism can even be useful in promoting productivity and life satisfaction. This observation led Hamachek [8] to distinguish between adaptive and maladaptive perfectionism. Hamachek refers to the former as "normal perfectionism," which he describes as deriving pleasure from assiduous effort, striving for excellence while giving oneself permission to be less than perfect, and experiencing satisfaction from a job well done. The normal perfectionist is able to accept both personal and circumstantial limitations, and maintains realistic expectations and reasonable goals. Personal strengths are acknowledged and drawn upon as one becomes 
emotionally invested in the task at hand. High levels of functioning are pursued to the maximum of one's ability while maintaining internal and external balance and in life. The normal perfectionist can be conceptualized as a less intense version of Frost's high personal standards and orderliness and Hewitt and Flett's self-oriented perfectionist. These personality traits exist along a continuum of severity, with the normal perfectionist exhibiting more functional versions that are associated with good work habits, resourcefulness, constructive striving, high achieving, and self-actualization.

Hamachek's conception of maladaptive perfectionism, which he refers to as "neurotic perfectionism," served in large part as the precursor to Frost and Hewitt and Flett's multidimensional perfectionism scales $[1,3]$. The neurotic perfectionist is driven by an intense fear of avoiding failure and the underlying feeling of not being good enough. The deep inner sense of inferiority drives the individual to push beyond natural limitations and to ignore bodily signs to slow down, such as tiredness or fatigue. Since the over striving never actually satisfies the need for perfection and approval from others, the individual becomes caught in a never-ending cycle of relentless pushing fueled by the threat of falling short, inevitable and crushing disappointment, and harsh self-blaming for not working hard enough, which eventually turns into self-loathing. Perfectionists consistently report that they should have done better, and they criticize their work as lower in quality than others. They are quick to blame themselves when a goal is not reached, even ignoring clear environmental limitations that rendered the goal unattainable. They are unable to feel satisfied from what others would generally consider a job well done or even an exceptional performance. Nothing is ever good enough, no effort is ever sufficient, and there is no way to redeem themselves from the depths of their own inadequacy.

These two categories have come to be known as Evaluative Concerns Perfectionism (ECP) and Personal Standards Perfectionism (PSP) in the literature [9]. ECP includes maladaptive factors that affect the way perfectionists assess their own value as individuals, which is generally based on fear, self-criticism, and inferiority. By contrast, PSP includes dimensions that have adaptive components, and has less to do with personal worth and more with a focus on positive striving. Studies show that these are largely independent factors, with PSP correlating with positive affect, life satisfaction, conscientiousness, and psychological endurance, and ECP corresponding with stress, negative affect, suicidal ideation, neuroticism and low self-esteem [10].

Researchers have examined how Blankstein and Dunkley's dimensions interact within the individual. Gaudreau and Thompson devised a $2 \times 2$ model that has received empirical support, which proposes four subtypes of perfectionism: low ECP/low PSP (non-perfectionists), high ECP/low PSP (pure ECP), high PSP/low ECP (pure PSP) and high ECP/high PSP (mixed perfectionists) [11]. Further research in needed to determine how to gauge ECP and PSP not at dichotomous variables (either high or low), as Gaudreau does, but instead to measure them on a continuous scale in order to account for meaningful variance [10].

\section{Etiology of Perfectionism}

How does perfectionism develop? Theorists generally point to early caregiving relationships to understand the source of this personality trait. Contributing factors include non-approving or inconsistently approving parents, or parents whose love is conditional upon the child's achievement $[8,12,13]$. Instead of experiencing unconditional acceptance by caregivers, these children absorb the message that their worth hinges upon their performance. Absent is the experience of knowing they are good enough to deserve love just as they are, and in its place is the constant threat of feeling worthlessness as a result of not living up to perceived standards of accomplishment. These children learn to overvalue performance and to pursue flawlessness as a means of gaining their parents' approval, which they rarely succeed in doing anyway. The mindset becomes that, "If I try a little harder, if I do a little better, if I become perfect, my parents will love me" [14]. This message may be conveyed in subtle ways, through a parent's disappointed facial expression, a sigh, or a change in voice tone. Nonetheless, the experience of the child is largely the same, namely that I have not lived up to my parents' expectations, that what I do and who I am is never good enough, and that next time I'll work harder to get it right.

Closely connected to conditional approval is the critical parenting style that perfectionistic parents display. The internal critical voice that characterizes perfectionistic inner dialogue can be thought of as an internal representation of the overly critical and demanding parental voice they heard as children [2]. Not surprisingly, these parents' internal selftalk sounds very similar to how they communicate with their children [15]. They berate themselves, belittle their own accomplishments, and rarely feel that they have achieved a good enough performance, which is probably related to internal representations of parental figures from their own childhoods. In this way, the perfectionistic pattern of harsh self-evaluation continues from one generation to the next in a cycle of internalized parental criticism, low feelings of selfworth, and expecting from their children what they have been falling short of achieving their whole lives.

Brown contends that perfectionism can be thought of as a means of running away from shame $[12,13]$. Shame or the fear of being unworthy of love, causes perfectionists to hide behind a facade of flawlessness so that no one discovers "their true unworthiness." It is a way of covering up what they see as the truth of who they are, and is fueled by the belief if someone sees behind my mask of perfection, they will not love me. Even a small failure is experienced as a major threat of being discovered and rejected. Just as parents did not accept me for who I am, the perfectionist thinks, surely no one else will. According to Brown, this is why perfectionists are so preoccupied with external approval, because they view others as holding the key to their own worth. This is also how Brown distinguishes between perfectionism and healthy striving. Healthy striving is self-focused, and is based on the question, "How can I improve?" Perfectionism is other-focused, and revolves around the question, "What will they think of me?" The pervasive fear that develops 
from the constant threat of coming face to face with their own worthlessness can create considerable anxiety and be the precursor to depressive symptomatology.

\section{Perfectionism and Anxiety and Depression}

Numerous studies have shown that perfectionism is a major risk factor for anxiety and depression [9]. Wheeler and colleagues found that people diagnosed with Social Anxiety Disorder (SAD) had higher scores of maladaptive perfectionism than those suffering from Panic Disorder or Obsessive-Compulsive Disorder (OCD) [16]. This may not be surprising given the defining features of SAD. Social anxiety sufferers are overly concerned with the scrutiny of others and are sensitive to criticism. They try to avoid embarrassment or rejection by performing perfectly in social settings. They worry about not meeting social expectations and often avoid situations that they fear will lead to perceived failure, and thus prefer solitude over social engagement. Many of these core symptoms are in common with Hewitt and Flett's Socially Prescribed Perfectionist, who believes that others set impossibly high standards and are never satisfied with their performance. Indeed, research has shown an association between Socially Prescribed Perfectionism and anxiety [17]. These perfectionists criticize themselves just as they assume others are doing. They live in fear of their mistakes and firmly believe they are deficient in their abilities to ever meet expectations and earn acceptance. It is not difficult to see the overlap between Socially and Self-Oriented Perfectionism, which is also characterized by concern over mistakes and intense self-criticism. In fact, Wheeler and colleagues found that SAD individuals reported the highest levels of selfcritical perfectionism of all study groups, equaled only by the depressed group [16]. However, McGrath, et al. did not find support for the claim that self-critical perfectionism makes people more vulnerable to increased levels of anxiety [18]. While research clearly suggests a concomitant link of cooccurring self-critical perfectionism and anxiety symptoms, further study is needed to understand the exact ways in which they influence one another [7].

The link between perfectionism and depression is well documented $[1-3,7,8,12,13,16]$. Using the Frost MPS, the strongest predictors of depression are concerns over mistakes and doubts about actions [16,19]. In Hewitt and Flett's model, the strongest predictor of depression was Socially Prescribed Perfectionism [20]. However, other findings show that Self-Oriented Perfectionism, which involves exceedingly high personal standards and relentless self-criticism, is also strongly correlated with increased rates of depression [2]. When viewed together, the picture of the depressed perfectionist seems to be of an individual, who experiences externally imposed, excessive standards over which they have no control, leaving them feeling resentful, helpless, and hopeless. They live in constant fear of making mistakes and under the burden of heavy self-criticism, and see now way out of their plight. Their sense of failure and utter despair can lead to suicidal thoughts and clinical depression.

Some suggest that the link between Socially Prescribed Perfectionism and depression may lie in a difficulty accepting past experiences as satisfying and meaningful [21]. People high in Socially Prescribed Perfectionism try to meet the expectations of others rather than living as their own authentic selves, and thus may feel like the life they lived was not their own. Perfectionism can also cause people to limit their experiences to those focused on achievement instead of pursuing meaningful social relationships and personal growth. In addition, they may look back at past events through a self-critical lens and berate themselves for their perceived failures [22]. The result is an inability to see their life experiences as purposeful and satisfactory, which directly correlates with feelings of low self-worth and other depressive symptoms [21].

\section{Treatment}

Clinicians have traditionally viewed perfectionism as a stable personality trait, which therefore makes it difficult to treat [23]. The persistent nature of this issue may come as a result of its deep roots in early parent-child relationships. From a pharmacological perspective, perfectionists who suffer from moderate to severe levels of depression and anxiety should meet with a psychiatrist to consider medication that has been proven effective in the treatment of these disorders [24].

The literature regarding effective psychological treatments distinguishes between low, moderate, and high levels of perfectionism. Individuals with low-to-moderate levels of perfectionism have been shown to be responsive to brief psychological treatment, such as Cognitive Behavioral Therapy [23]. Furthermore, individuals who display middle levels of perfectionism have reported that the therapeutic relationship plays an important role in treatment [2]. The perceived quality of the therapeutic relationship may be of particular importance to those patients suffering from Social Prescribed Perfectionism precisely because of the interpersonal nature of the issue. The therapist can model unconditional acceptance, realistic goal setting, empathy in the face of failure and complimentary feedback to support and encourage incremental progress.

Regarding those who display high levels of pervasive, deeply rooted perfectionism, research indicates that longterm therapy is most effective [2,23]. Blatt suggests that intensive, psychodynamic treatment can help individuals let go of their identification with harsh, judgmental, parental figures and redefine themselves outside the high expectations set for them from an early age [2]. Glover argue that a schema-focused approach can also facilitate meaningful change for highly perfectionistic individuals [23]. Schema work can help people identify patterns that developed at a young age that keep them locked into maladaptive ways of thinking, feeling, and behaving [25]. Clinicians have also pointed to Acceptance and Commitment Therapy (ACT) as a model that can help perfectionists deal with distressing cognitions, such as harsh self-criticism, and emotions, such as anxiety and depression, through learning how to mindfully and nonjudgmentally accept these inner experiences while moving toward more meaningful ways of living $[21,26]$. Brown claims that the underlying goal of all work with perfectionistic individuals should be to relearn the basic truth 
of their worthiness $[12,13]$. Just as the disturbance can be thought of as a means of distancing oneself from shame, so too must all meaningful change be about arriving at the deep acknowledgment of one's own worth without prerequisites. Perfectionists can learn to let go of the need for approval and reclaim the deep inner knowledge that they are good enough to be deserving of love and acceptance in this very moment. With time, commitment, and practice, these individuals can come out of hiding behind a facade of fabricated perfection and can embrace themselves and the people around them just as they are.

\section{Conclusion}

The rigid and overbearing nature of perfectionism makes it a particularly difficult problem to address. Besides the longstanding patterns of self-critical thinking, fear, inferiority, shame, anxiety and depressive symptoms, perfectionists have been known to reject help from mental health professionals because it implies that they are flawed. A working therapeutic alliance can be difficult to establish with perfectionistic patients [27] and therapy does not always yield positive results. Nonetheless, some long-term therapies have been proven effective with this difficult population. Helping professionals as well as those living with perfectionistic individuals should understand that behind the challenging and demanding exteriors are individuals who are scared of being vulnerable, worried about being discovered and in need of help. Clinical advances over the last several decades provide a promising direction for treatment in this area. As has been shown, important steps are being taken in the process of helping perfectionists live happier, more satisfying, meaningful lives.

\section{References}

1. Hewitt PL, Flett GL. Perfectionism in the self and social contexts: Conceptualization, assessment, and association with psychopathology. J Pers Soc Psychol. 1991;60(3):456-70.

2. Blatt SJ. The destructiveness of perfectionism. Am Psychol. 1995;50(12):1003-20.

3. Frost RO, Marten P, Lahart CM, et al. The dimensions of perfectionism. Cogn Ther Res. 1990;14:449-68.

4. Hewitt PL, Flett GL. Dimensions of perfectionism, daily stress, and depression: A test of the specific vulnerability hypothesis. J Abnorm Psychol. 1993;102:58-65.

5. Hewitt PL, Flett GL, Turnbull-Donovan W. Perfectionism and suicidal potential. Br J Clin Psychol. 1992;31:181-90.

6. Dunkley DM, Blankstein KR. Self-critical perfectionism, coping, hassles and current distress: A structural equation modeling approach. Cogn Ther Res. 2000;24:713-30.

7. Sherry SB, Richards JE, Sherry DL, et al. Self-critical perfectionism is a vulnerability factor for depression but not anxiety: A 12 month, 3 wave longitudinal study. J Res Pers. 2014;52:1-5.

8. Hamachek DE. Psychodynamics of normal and neurotic perfectionism. Psychology. 1978; 15:27-33.
9. Blankstein KR, Dunkley D. Evaluative concerns, self-critical and personal standards perfectionism: A structural equation modeling strategy. Perfectionism: Theory, research and treatment, American Psychological Association, Washington, DC. 2002;285-315.

10. Taylor JJ, Papay KA, Webb JB, et al. The good, the bad and the interactive: Evaluative concerns perfectionism moderates the effect of personal strivings perfectionism on self-esteem. Pers Individ Dif. 2016;95:1-5.

11. Gaudreau P, Thompson A. Testing a 2 x 2 model of dispositional perfectionism. Pers Individ Dif. 2010;48(5):532-37.

12. Brown B. The gifts of imperfection: Let go of who you think you're supposed to be and embrace who you are. Hazelden, Center City, MN. 2010.

13. Brown B. Daring greatly: How the courage to be vulnerable transforms the way we live, love, parent, and lead. Gotham Books, New York, NY. 2012.

14. Hollender MH. Perfectionism. Compr Psychiatry. 1965;6:94-103.

15. Missildine WH. Perfectionism-If you must strive to "do better". Your inner child of the past, Pocket Books, New York, NY. 1963;75-90.

16. Wheeler HA, Blankstein KR, Antony MM, et al. Perfectionism in anxiety and depression: Comparisons across disorders, relations with symptom severity and role of comorbidity. Int J Cogn Ther. 2011;4(1):66-91.

17. Klibert JJ, Langhinrischen-Rohling J, Saito M. Adaptive and maladaptive aspects of self-oriented versus socially prescribed perfectionism. J Coll Stud Dev. 2005;46:141-156.

18. McGrath DS, Sherry SB, Stewart SH, et al. Reciprocal relations between self-critical perfectionism and depressive symptoms. Can J Behav Sci. 2012;44:169-81.

19. Frost RO, Heimberg RG, Holt CS, et al. A comparison of two measures of perfectionism. Pers Individ Dif. 1993;14:119-26.

20. Sherry SB, Hewitt PL, Flett GL, et al. Perfectionism dimensions, perfectionistic attitudes, dependent attitudes, and depression in psychiatric patients and university students. J Couns Psychol. 2003;50:373-86.

21. Sherry DL, Sherry SB, Hewitt PL, et al. The existential model of perfectionism and depressive symptoms: Tests of incremental validity, gender differences and moderated mediation. Pers Individ Dif. 2015;76:104-10.

22. Mushquash A, Sherry SB, Stewart SH, et al. The existential model of perfectionism and depressive symptoms: A short-term, four-wave longitudinal study. J Couns Psychol. 2010;57:423-48.

23. Glover DS, Brown GP, Fairburn CG, et al. A preliminary evaluation of cognitive-behaviour therapy for clinical perfectionism: A case series. $\mathrm{Br} \mathrm{J}$ Clin Psychol. 2007;46:85-94. 
24. Preston J, Johnson J. Clinical Psychopharmacology made ridiculously simple (8th Edn). MedMaster, Inc., Miami, FL 2016.

25. Young JE, Klosko JS, Weishaar ME. Schema therapy: A practitioner's guide. Guilford Press, New York, NY. 2006.

26. Hayes S. Acceptance and commitment therapy, relational frame theory and the third wave of behavioral and cognitive therapies. Behav Ther. 2004;35:639-65.

27. Zuroff DC, Blatt SJ, Sotsky SM, et al. Relation of therapeutic alliance and perfectionsim to outcome in brief outpatient treatment of depression. J Consult Clin Psychol. 2000;68(1):114-24.

\section{*Correspondence to:}

Nadira T Pardo

California Southern University

USA

Tel: 0411674986

E-mail: Nadira.Pardo@my.calsouthern.edu 